\title{
A diagnostic study of monsoon energetics for two contrasting years
}

\author{
S. S. V. S. Ramakrishna ${ }^{1}$, V. Brahmananda Rao ${ }^{1,2}$, A. Sravani ${ }^{1}$, N. Vijaya Saradhi ${ }^{1}$, and G. Harikishan ${ }^{1}$ \\ ${ }^{1}$ Department of Meteorology \& Oceanography, Andhra University, Visakhapatnam-530003, India \\ ${ }^{2}$ Instituto Nacional de Pesquisas Espaciais, INPE. São José dos Campos, S.P, Brazil
}

Received: 13 July 2010 - Revised: 29 November 2010 - Accepted: 30 November 2010 - Published: 21 December 2010

\begin{abstract}
In the present study we made an attempt to explain the behavior of the southwest monsoon for two contrasting years, from the view point of energetics. As a test case we selected 2002 and 2003, which were weak and strong monsoon years, respectively, based on rainfall. The energy terms $K \psi, K \chi$ and APE and the conversion terms $f \nabla \psi . \nabla \chi$, $-\omega^{\prime} T^{\prime}$ are calculated at $850 \mathrm{hPa}$ level and also vertically integrated from $1000 \mathrm{hPa}$ to $100 \mathrm{hPa}$. The results indicate that, the year of high energy (both $K_{\Psi}, K_{\chi}$ ) i.e. 2002, does not give a good amount of rainfall compared to the good year i.e. 2003. The break period during the year 2002 has been clearly explained using the block diagrams. Periods of highest rainfall coincide with the positive conversions of $f \nabla \psi$. $\nabla \chi$ and $\overline{-\omega^{\prime} T^{\prime}}$. Vertically integrated moisture fluxes during the break period of 2002, 2003 are also analyzed. The main reservoirs (sources and sinks) for the monsoon energy are also identified using block diagrams. Negative correlation between daily rainfall and energy terms in the year 2002 indicates its unusual behavior both in terms of energetics as well as precipitation. Positive correlations in the year 2003 represent strong monsoonal behavior. We calculated the climatology of the total kinetic energy at $850 \mathrm{hPa}$, vertically integrated (1000-100 hPa) for 30 years (1980-2009) and rainfall for 103 years (1901-2003) which clearly indicates that the monsoon is indeed a season of high energy for the South Asian region.

Also the east- west direct thermal circulations are strongly related to the good and bad monsoon years.
\end{abstract}

Keywords. Meteorology and atmospheric dynamics (General circulation; Precipitation; Tropical meteorology)

Correspondence to:

S. S. V. S. Ramakrishna

(ssvs_rk@yahoo.co.in)

\section{Introduction}

The Indian monsoon system plays a major role in the atmospheric general circulation. Forecasting of such a principle component can be improved by a careful diagnostic analysis of the properties of various flow regimes. One of the basic properties associated with the atmospheric motion is its energetic behavior. In a seminal paper Lorenz (1960) mentioned that "one enlightening method of studying the atmosphere or a portion of it consists of examining the behavior of the energy involved". For the past half a century scientists have been pondering on the diagnostic studies of atmospheric energy levels and its energy sources, sinks and transformations. The atmosphere is set in motion basically due to the conversion of (total) potential energy to kinetic energy. The two forms of energy relevant to the atmosphere are kinetic energy and the available potential energy. The latter was originally introduced by Lorenz (1955) who also provided a decomposition of Energetics into their zonal mean and eddy parts. From a view point of thermodynamics, the atmosphere may be regarded as a "heat engine", which absorbs net heat at relatively warm temperatures in the tropics (release of latent heat due to evaporation from sea surface) and gives up heat at relatively cool temperatures in the extra-tropics. In this way the net radiation generates available potential energy, which in turn partially gets converted to kinetic energy, and does work to maintain the circulation against the frictional dissipation. For an idealized circulation in the absence of eddy sources, the differential diabatic heating would be balanced only by adiabatic cooling near the equator and adiabatic warming near the poles (Holton, 2004).

With advances in monsoon research, meteorologists have expanded the Ramage's definition (Ramage, 1971) and are looking into the entity from a planetary scale perspective. From the combination of wind direction and rainfall, the general criterion of the monsoon definition is its winter/summer reversal in wind direction and a wet alternation with a dry 


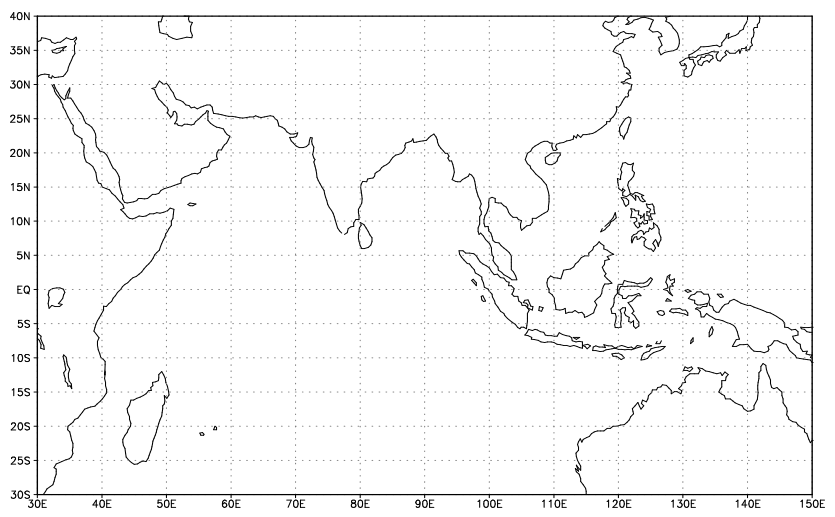

Fig. 1. Selected domain for the study.

period on a seasonal basis (Jianjun and Guoxiong, 1999). Climatologically the summer monsoon circulation (JuneSeptember) over the Indian sub-continent is of great significance because a large fraction $(71 \%)$ of the total annual rainfall over most of India is accounted by this season (Parthasarathy, et al., 1994). The summer monsoon rainfall for 1 July to 30 September for India as a whole during 2002 (2003) was $81 \%$ (102\%) of its long period average (LPA) (Source: Department of Science \& Technology, http://www.imd.gov.in).

It is well known that the rainfall distribution over India varies considerably day to day. Over a major portion of the country, rain occurs in spells under the influence of favorable circulation conditions. The Indian monsoon system forms a major branch in the atmospheric general circulation and is characterized by the evolution of the kinetic energy which is maintained by the entry and exit of energy into this magnificent heat engine. During the advent of the monsoon, the different phases of its life cycle are manifested by the changes in the generation of kinetic energy (pre onset, onset, active, break and withdrawal). Several studies have been attempted to explain the mechanism of these contrasting behavior for two years (Raju et al., 2002; Dimri, 2005; Awade et al., 1982; Ramesh et al., 1994; Krishnamurti, 1998).

The objective of this study is to focus on the dry and wet spells operating on different time scales, which can be diagnosed by computing the co-variances of $f \nabla \psi \cdot \nabla \chi, \overline{-\omega^{\prime} T^{\prime}}$ and also to examine the interannual variation of Energetics during different epochs of the monsoon and their interaction and if possible the changes occurring at the onset phase of the Indian monsoon system.

\section{Data and methodology}

The main data sets for this study are derived from the Nation Centre for Environmental Prediction (NCEP) and National Centers for Atmospheric Research (NCAR) Reanalysis 1 (Kalnay et al., 1996; Kistler, 2001). The data consists of daily 4 values (00:00, 06:00, 12:00 and 18:00 GMT) of temperature, geopotential height and the component winds in all the three directions for the two years 2002 and 2003 at 17 pressure levels with a horizontal resolution of $2.5^{\circ}$ by $2.5^{\circ}$. The high resolution $1^{\circ} \times 1^{\circ}$ gridded daily rainfall data of India has been taken for the two years 2002 and 2003 from Rajeevan et al. (2006).

The methodology of this study consists of considering a selected domain large enough such that boundary fluxes may not contribute significantly to the conversions $\left(30^{\circ} \mathrm{S}-40^{\circ} \mathrm{N}\right.$; $30^{\circ} \mathrm{E}-150^{\circ} \mathrm{E}$ ) (Fig. 1), for a period of 122 days (1 June to 30 September) of each year. The computed values are plotted for the entire Monsoon regime. This is to examine whether these co- variances operate with any time lag or not and if so at what time difference.

\section{$\psi-\chi$ interactions}

The conventional breakdown of the horizontal wind $V_{\mathrm{H}}$ into irrotational and nondivergent components may be expressed by the relations (Krishnamurti et al., 1998)

$V_{\mathrm{H}}=V_{\Psi}+V_{\chi}$

$V \psi=k X \nabla \psi$

$V \chi=\nabla \chi$

Here $\Psi$ is the stream function and $\chi$ the velocity potential. The energy equations in terms of these components are usually expressed by the relations (Krishnamurti et al., 1998)

Rotational kinetic energy $\left(K_{\psi}\right)$ :

$\frac{\partial K_{\psi}}{\partial t}=\left\langle K_{\chi}, K_{\psi}\right\rangle-D_{\psi}+B_{\psi}$

Divergent kinetic energy $\left(K_{\chi}\right)$ :

$\frac{\partial K_{\chi}}{\partial t}=\left\langle P, K_{\chi}\right\rangle-\left\langle K_{\chi}, K_{\psi}\right\rangle-D_{\chi}+B_{\chi}$

$\left\langle P, K_{\chi}\right\rangle=-\chi g \nabla^{2} z$. Here $D$ denotes dissipations and $B$ denotes boundary flux terms and $\left\langle K_{\chi}, K_{\psi}\right\rangle$ denotes the net barotropic energy exchange, $\left\langle P, K_{\chi}\right\rangle$ denotes the net Hadley type and east-west over turning. The above equations describe the Energetics of the monsoon system. The various components of energy equations are defined by relations:

$$
\begin{aligned}
&\left\langle K_{\chi}, K_{\psi}\right\rangle= f \nabla \psi \cdot \nabla \chi+\nabla^{2} \psi(\nabla \psi \cdot \nabla \chi)+\omega J\left(\psi, \frac{\partial \chi}{\partial p}\right) \\
&+\nabla^{2} \chi \frac{(\nabla \psi)^{2}}{2} \\
& K_{\psi}= \frac{1}{2}\left(u_{\psi}^{2}+v_{\psi}^{2}\right) \\
& K_{\chi}=\frac{1}{2}\left(u_{\chi}^{2}+v_{\chi}^{2}\right)
\end{aligned}
$$


The energy relations that are used in the case of vertical integration

$K_{\psi}=\frac{1}{g} \int_{p} \int_{y} \int_{x} \frac{\left(u_{\psi}^{2}+v \psi^{2}\right)}{2} d x d y d p$

$K_{\chi}=\frac{1}{g} \int_{p} \int_{y} \int_{x} \frac{\left(u_{\chi}^{2}+v \chi^{2}\right)}{2} d x d y d p$

$A P E=\frac{1}{g} \int_{p} \frac{\bar{T}}{\gamma_{d}-\bar{\gamma}}{\overline{\left[\frac{T^{\prime}}{\bar{T}}\right.}}^{2} d p$

All the energy conversions that are present in the equations from (4)-(8), are diagrammatically represented in the Fig. 2. In the tropics the main energy source is the generation $\overline{H^{\prime} T^{\prime}}$. After that it is converted as different energy terms through different conversions process and is shown in Fig. 2. We included main energy terms and conversions and neglected the dissipation and boundary fluxes. The daily variation of the energy quantities such as total kinetic energy $(K)$, rotational kinetic energy $\left(K_{\psi}\right)$ and divergent kinetic energy $\left(K_{\chi}\right)$ for the entire period of monsoon regime are computed.

The explanation of each term in Eqs. (2) and (3) was given by Krishnamurti et al. (1998). The magnitude of the term $f \nabla \psi . \nabla \chi$ depends on the orientation of the vectors $\nabla \psi$, and $\nabla \chi$. The second term, $\nabla^{2} \psi(\nabla \psi . \nabla \chi)$ in Eq. (4) denotes the cyclonic vorticity effect on kinetic energy equations of the rotational and divergent components. The term $\omega J\left(\frac{\partial \chi}{\partial p}\right)$ in the Eq. (4) expresses the role of vertical motion in kinetic energy change. The term $\nabla^{2} \chi \frac{(\nabla \psi)}{2}^{2}$ depends on the covariance of the kinetic energy of the rotational component $K \psi=(\nabla \psi \nabla \chi) / 2$.

\section{A brief overview of 2002 and 2003}

The 2002 Southwest monsoon is characterized by a long break, i.e. below normal rainfall throughout the month of July. Season-wise, it was the first "All-India Drought" after a continuous spell of the normal/good monsoons that followed the previous "All-India drought" of 1987. The onset date is 29 May which is three days before the climatological date. The seasonal rainfall (June-September) for the country as a whole was $19 \%$ below normal. 15 out of 36 meteorological sub-divisions covering $44 \%$ area of the country received normal to excess rainfall. Two out of the remaining 21 sub-divisions viz., East Rajasthan and West Rajasthan were in the scanty category (negative rainfall departure more than $-59 \%)$, whereas the rest of 19 were in the deficient category (rainfall departure $-20 \%$ to $-59 \%$ ). Out of 523 meteorological districts, $272(53 \%)$ received deficient rainfall and 40 $(8 \%)$ were in scanty category $172(33 \%)$ of the districts experienced normal rainfall and only $33(6 \%)$ had excess rainfall. On All-India level, July rainfall deficiency was 51\%, the

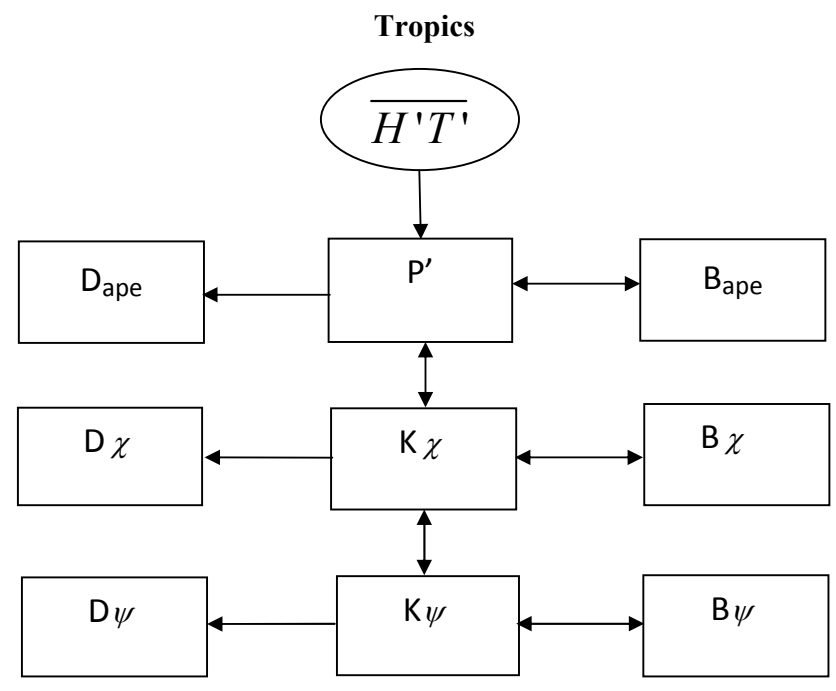

Fig. 2. The above figure clearly indicates the basic transformation of energy in the tropics. The various boxes denote different energy exchanges and units are $\mathrm{m}^{2} \mathrm{~s}^{-3}$.

worst in the history of recorded observations. The combined June-July deficiency was $30 \%$, which also has few parallels. There was a remarkable recovery in August that saved the situation from further worsening (reference, Indian Meteorological Department (IMD) end of Monsoon report 2002 and 2003). On the contrary, during 2003 Southwest monsoon season, no well defined break periods were seen longer than a week. Precipitation time series are marked by a relatively steady rainfall although a little less than normal from day to day throughout the season. In particular, the 2003 summer was devoid largely of low rainfall days. Some distinct active periods are seen around 20 June, 15 July, 30 July, and the first and last week of September. The onset of the southwest monsoon over Kerala occurred on 8 June, a week after its normal date of onset 1 June. According to the India Meteorological Department, monsoon precipitation between 1 June and 17 September was normal or excess in 33 of the 36 meteorological subdivisions. This situation is deemed to be the best in the past five years. Despite being in withdrawal, the monsoon brought heavy showers during the week ended 17 September in Goa, parts of Maharashtra, Uttar Pradesh, Madhya Pradesh, West Bengal and the Northeast. Moderate rainfall was recorded in parts of Rajasthan, Gujarat and Karnataka. However, 12 subdivisions received scanty rainfall during this week, largely because the monsoon has withdrawn from the northwestern region (National Climate Center reports - IMD 2002, 2003). Figure 3 shows the time series of daily rainfall.

We divided the entire monsoon season into three periods depending upon the daily normal rainfall curve (averaged over the period 1951-2000) shown in the Fig. 2a, b. They are 

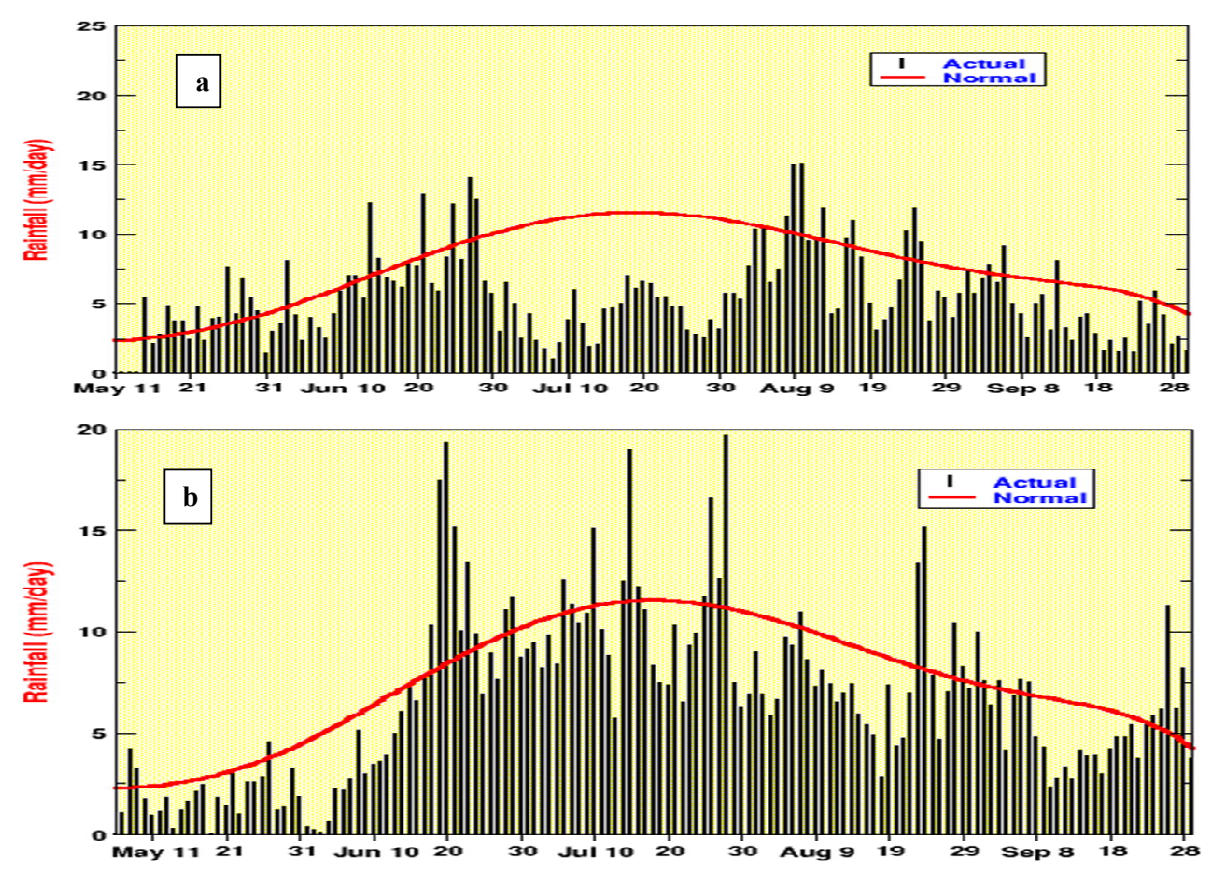

Fig. 3. Time series of daily precipitation for India as whole for monsoon 2002 (upper Panel) and monsoon 2003 (lower panel). Solid curve represents daily normal (1951-2000) smoothed values.

1. 10 June-30 June (Before break)

2. 1 July-10 August (break)

3. 11 August-30 August (after break).

\section{Results}

In the present study we made an attempt to study the relationship between different energy terms and their variations. The selected domain has dimensions $30^{\circ} \mathrm{S}-40^{\circ} \mathrm{N}$ and $30^{\circ} \mathrm{E}-$ $150^{\circ} \mathrm{E}$ (Fig. 1). Figure $4 \mathrm{a}$ and $\mathrm{b}$ indicates, respectively, the variation of 30 years mean total kinetic energy at $850 \mathrm{hPa}$ and vertically integrated kinetic energy values and 103 years mean rainfall during the entire 12 months. Figure 4a indicates a steady raise of the total kinetic energy at $850 \mathrm{hPa}$ from the month of May reaching a maximum of $124 \mathrm{~m}^{2} \mathrm{~s}^{-2}$ in July, but the vertically integrated total kinetic energy is almost similar except that the variation near the peak is less sharp compared to that at $850 \mathrm{hPa}$ shown in Fig 4a. The mean rainfall for the 103 years shows a peak in the month of July. This clearly shows that the monsoon is a season of high energy in the South Asian region (the total kinetic energy in the monsoon season has a clear annual cycle with a maximum in the summer monsoon season). This is not unexpected because in the tropics the source of kinetic energy is the rainfall (Holton, 2004). However, in Fig. 4 it can be seen that in winter season (NDJ) there is a secondary maximum of kinetic energy which probably may be due to the winter monsoon. In any case the kinetic energy maximum in the month of July is about $75 \%$ more than that in December. The secondary maximum of kinetic energy in the winter partly reflects the baroclinic conversions and an example of generation of disturbances due to baroclinic instability such as western disturbances. These western disturbances are known to be generated due to Baroclinic Instability (Rao and Rao, 1971).

Figure 5 shows the time variation of total kinetic energy at $850 \mathrm{hPa}$ over the Arabian Sea domain $\left(5^{\circ} \mathrm{N}-25^{\circ} \mathrm{N}, 48^{\circ} \mathrm{E}-\right.$ $72^{\circ} \mathrm{E}$ ) for the years 2002,2003 and these are compared with the mean values (1990-2009).A few days before the onset of monsoon 2002 i.e., around 6 June there is a maximum in the total kinetic energy, and for the 2003 there is a sharp raise of total kinetic energy on 6 June which shows dynamical the onset on 10 June two days after the onset date shown in Fig. 4 (Krishnamurti and Ramanathan, 1982). Also, the 20 year mean kinetic energy seems to increase from 1 May through 30 June, as seen in Fig. 4. The vertically integrated $(1000 \mathrm{hPa}$ to $100 \mathrm{hPa})$ total kinetic energy is shown in the Fig. 6. There are two kinetic energy axes, one for 2002 on the left side and 2003 on the right side. The basic reason to make two axes is, during 2003 more energy has been released which is greater than that of 2002 and to show the variations clearly we have chosen the axes in this way. In the year 2003 there are two peaks which occur on 21 July and 11 August. In the rainfall pattern of 2003 (Fig. 3b) a peak occurred on 18 July and another one on 31 July. In Fig. 6, it is clearly observed that the total KE increased from 9 July to 21 July. This precedes the maximum rainfall peaks in the month of July during 2003. Similarly in 2002 total kinetic energy starts 


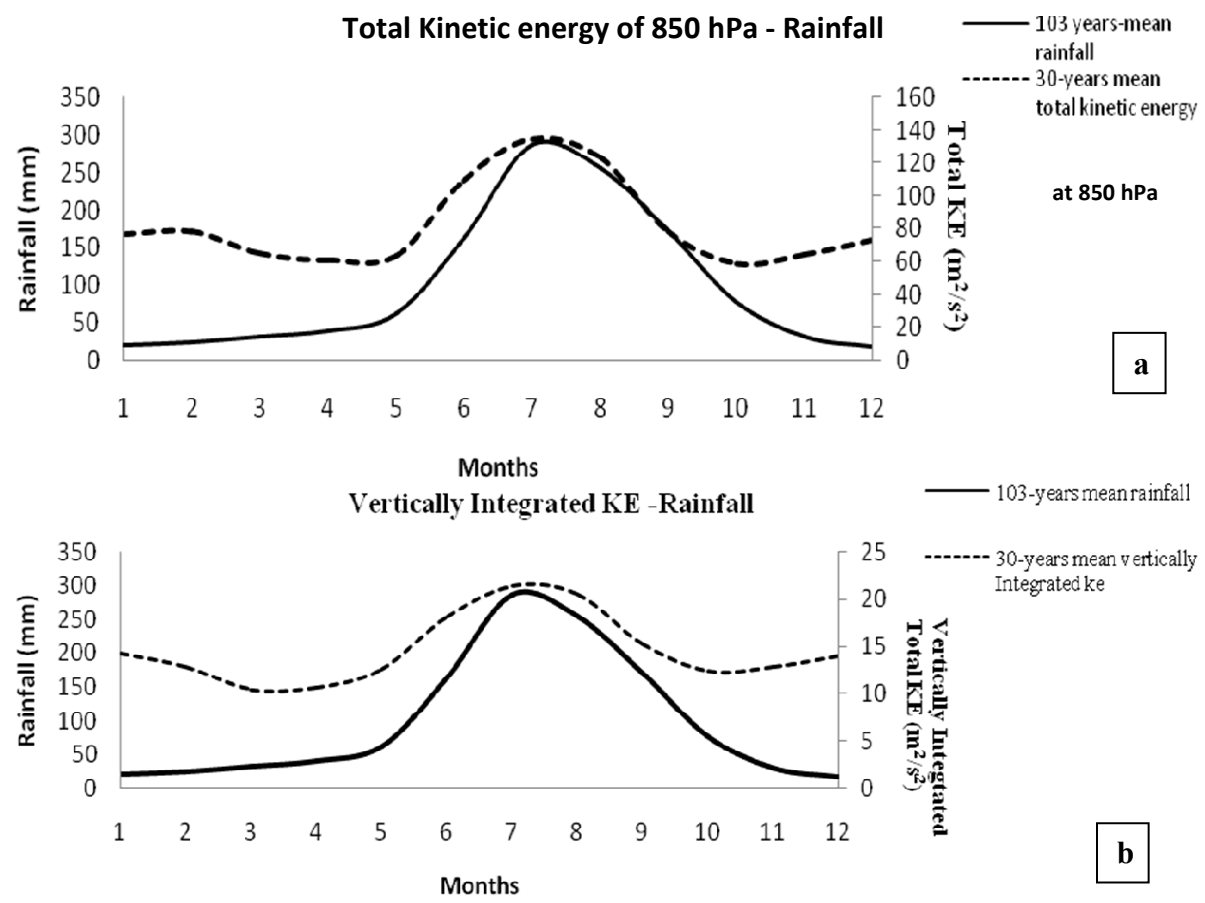

Fig. 4. Time series of monthly rainfall (103 years mean 1901-2003) for 12 months compared with the total kinetic energy at $850 \mathrm{hPa}$ ( 30 years mean 1980-2009) and vertically integrated (1000-100 hPa) total kinetic energy (30 years mean 1980-2009).

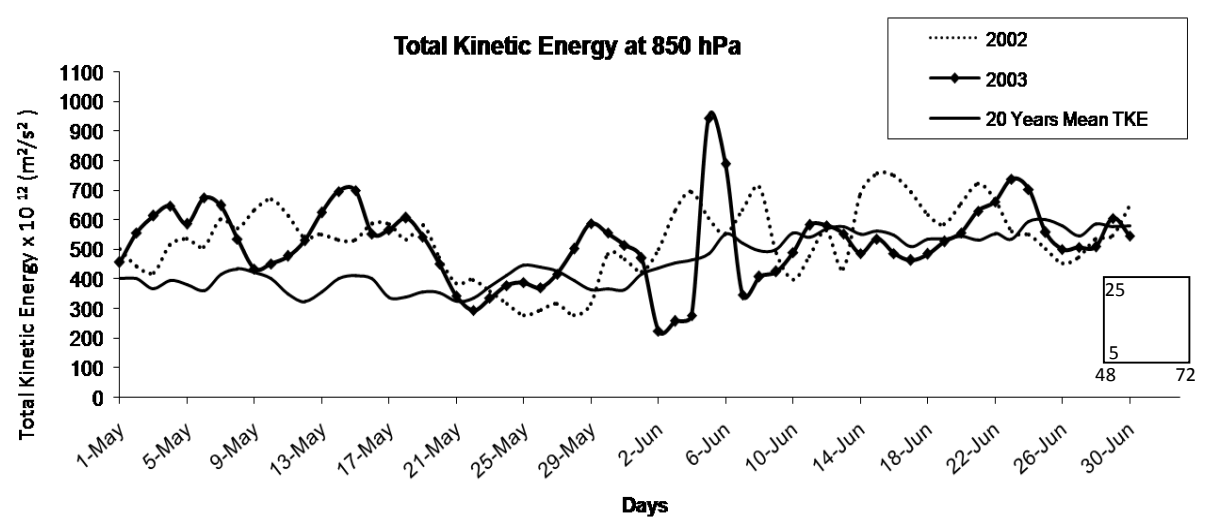

Fig. 5. Variation of Total kinetic energy from 1 May-30 June during 2002 and 2003 over the domain $48^{\circ} \mathrm{E}-72^{\circ} \mathrm{E}$ and $5^{\circ} \mathrm{N}-25^{\circ} \mathrm{N}(\mathrm{Arabian}$ Sea domain) compared with the mean total kinetic energy (1990-2009).

increasing from 6 July and reaches its minimum value on 15 July, where as rainfall during 2002 follows a decreasing pattern and the minimum rainfall occurred over period 10 July to 30 July.

Figure $7 \mathrm{a}$ and $\mathrm{b}$ shows, respectively, the vertically integrated $(1000 \mathrm{hPa}$ to $100 \mathrm{hPa})$ rotational kinetic energy $\left(K_{\Psi}\right)$ and divergent kinetic energy $\left(K_{\chi}\right)$. As expected most of the total kinetic energy is dominated by the rotational component. Figure 7 a shows that in the year $2003 K_{\Psi}$ increases continuously in the month of July when the rainfall attains its maximum value. A decreasing trend in the rotational kinetic energy in the month of July for the year 2002 is as- sociated with the decreased rainfall. Even though the rotational kinetic energy was higher during 2002, it did not help the monsoon to be good. In Fig. $7 b$, it can be seen in general that $(K \chi)$ is higher in 2002 compared to 2003 (note the scale difference in the ordinate). This suggests that the higher rainfall in 2003 need not necessarily reflect in the divergent kinetic energy values. This seemingly unrealistic result infact may occur and can be explained. Rainfall (or condensation heating) generates the available potential energy through the term $\overline{H^{\prime} T^{\prime}}$ which represents the correlation between the condensation heating and temperature. This indicates that the higher rainfall need not necessarily generate 


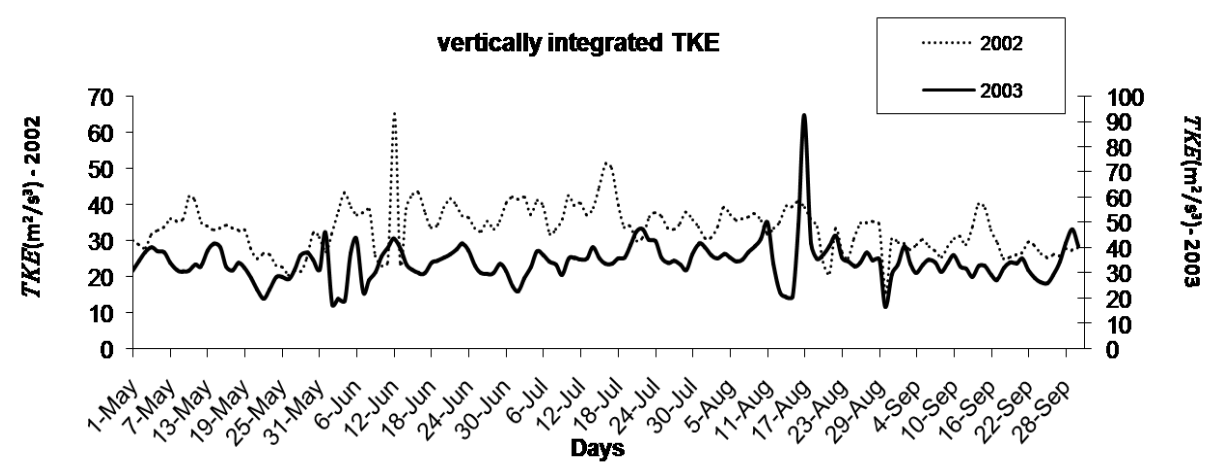

Fig. 6. Variation of Vertically Integrated (1000-100 hPa) total kinetic energy from 1 May-30 September during 2002 and 2003.

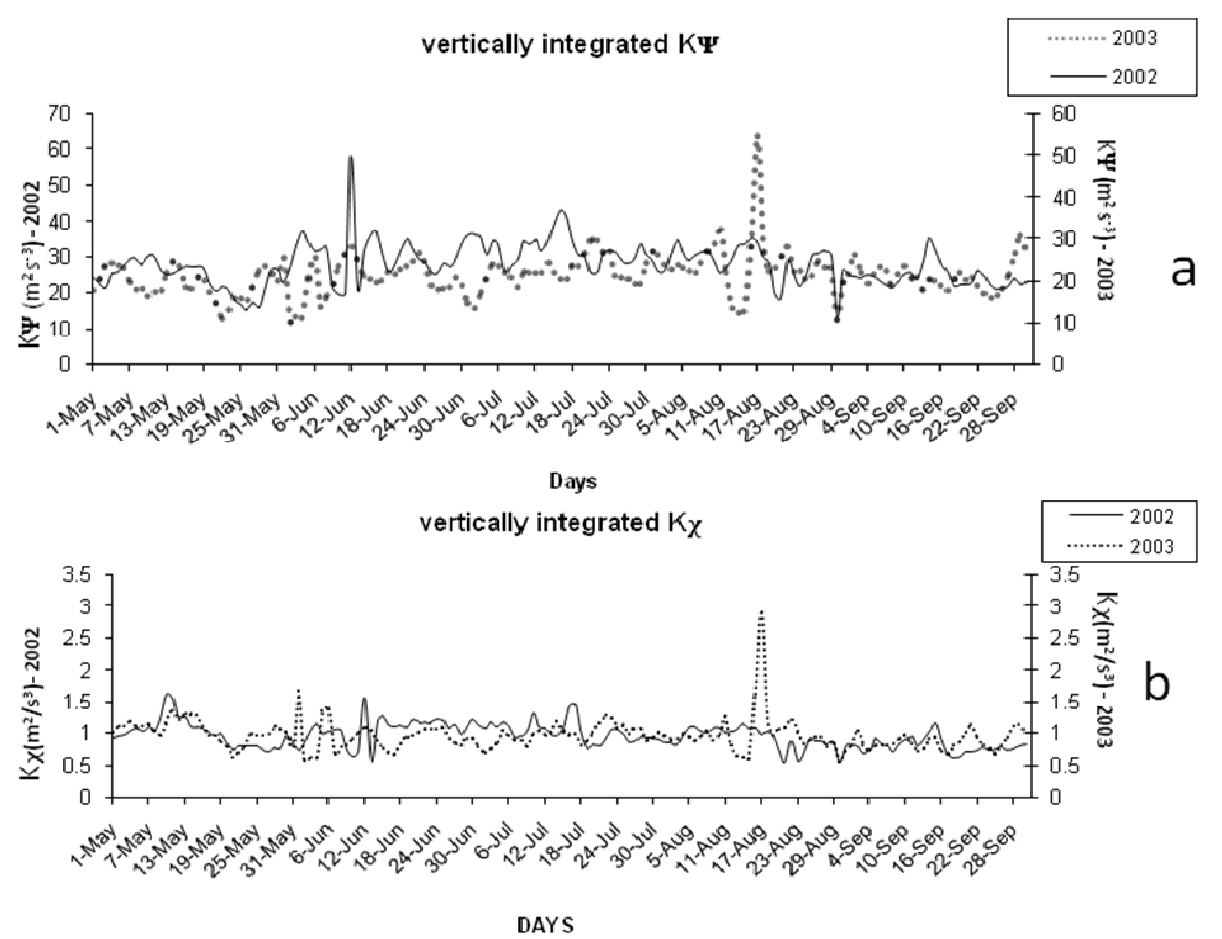

Fig. 7. Variation of Vertically Integrated $(1000-100 \mathrm{hPa})$ kinetic $\left(K_{\Psi}\right.$ and $\left.K \chi\right)$ energy from 1 May-30 September during 2002 and 2003 for the domain $30^{\circ} \mathrm{S}-40^{\circ} \mathrm{N}$ and $30^{\circ} \mathrm{E}-150^{\circ} \mathrm{E}$ shown in panels (a), (b), respectively.

higher available potential energy and thus need not result in higher conversion in $(K \chi)$. Figure 8 shows the graph of vertically integrated values $(1000-100 \mathrm{hPa})$ of $f \nabla \psi \nabla \chi$ during the 2002 and 2003 monsoon seasons averaged over the domain of $30^{\circ} \mathrm{S}-40^{\circ} \mathrm{N}$ and $30^{\circ} \mathrm{E}-150^{\circ} \mathrm{E}$. In Fig. 8, it can be seen, during the two years, there seems to be a continuous decrease of this term after the onset of monsoon. Also we find that this term is somewhat higher in the weak monsoon year 2002. This again suggests, as pointed out earlier, higher rainfall alone need not generate higher kinetic energy. Conversion of kinetic energy between rotational component and divergent components mainly depends on the $\Psi, \chi$ interactions. In those interactions the term $f \nabla \psi \cdot \nabla \chi$ plays a ma- jor role. Figure $9 \mathrm{a}$ and $\mathrm{b}$ illustrates the vertically integrated 1000-300 hPa moisture flux for the period 1 July-10 August 2002 (break period of 2002). As expected a clear cross equatorial transport of moisture from Southern to Northern Hemisphere along the Eastern coast of Africa entering the peninsular India is seen. This feature is well known as observed by Chen (1985). The dominantly higher flux during the good monsoon of 2003 can also be seen clearly.

\subsection{Energy exchange for three periods}

Figure 10 indicates the overall energetics and maintenance of the Monsoon system for the two contrasting years 2002 and 2003. The boxes in the figure illustrate the $\Psi, \chi$ interactions. 


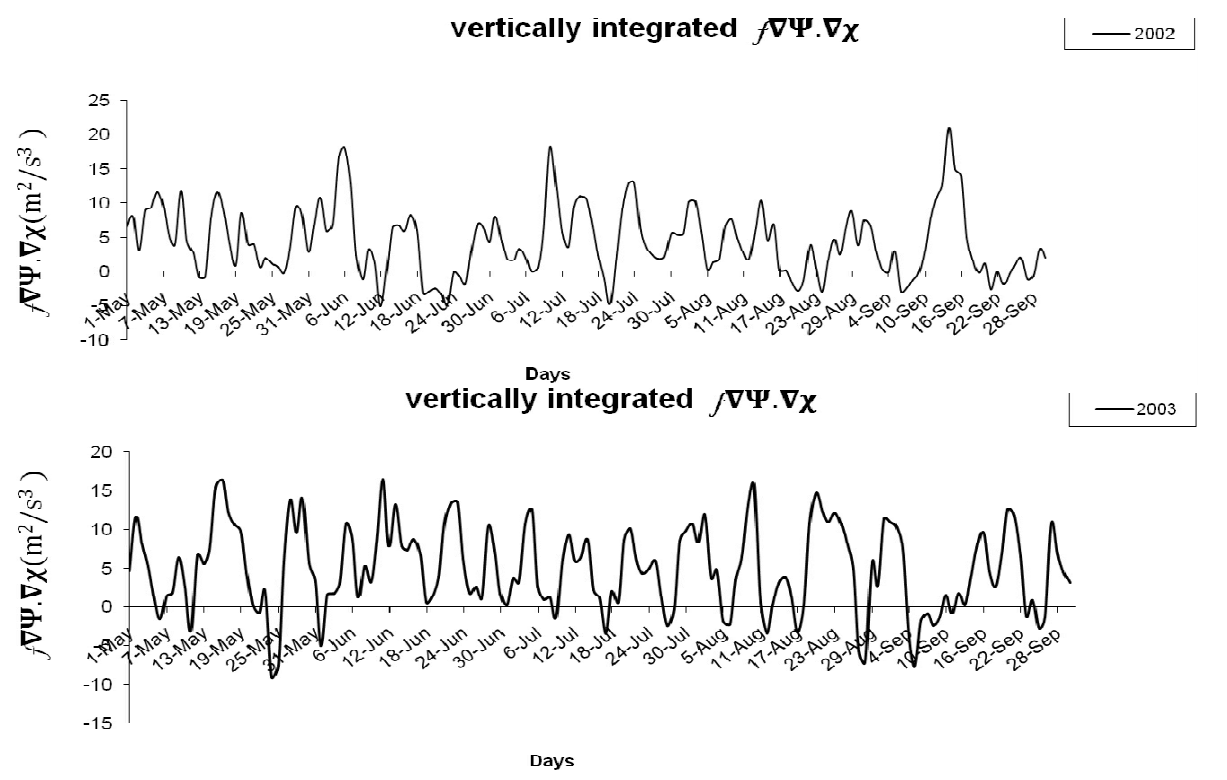

Fig. 8. Vertically Integrated (1000-100 hPa) $f \nabla \psi \cdot \nabla \chi$ from 1 May-30 September during 2002 and 2003 over the domain $30^{\circ} \mathrm{S}-40^{\circ} \mathrm{N}$ and $30^{\circ} \mathrm{E}-150^{\circ} \mathrm{E}$.

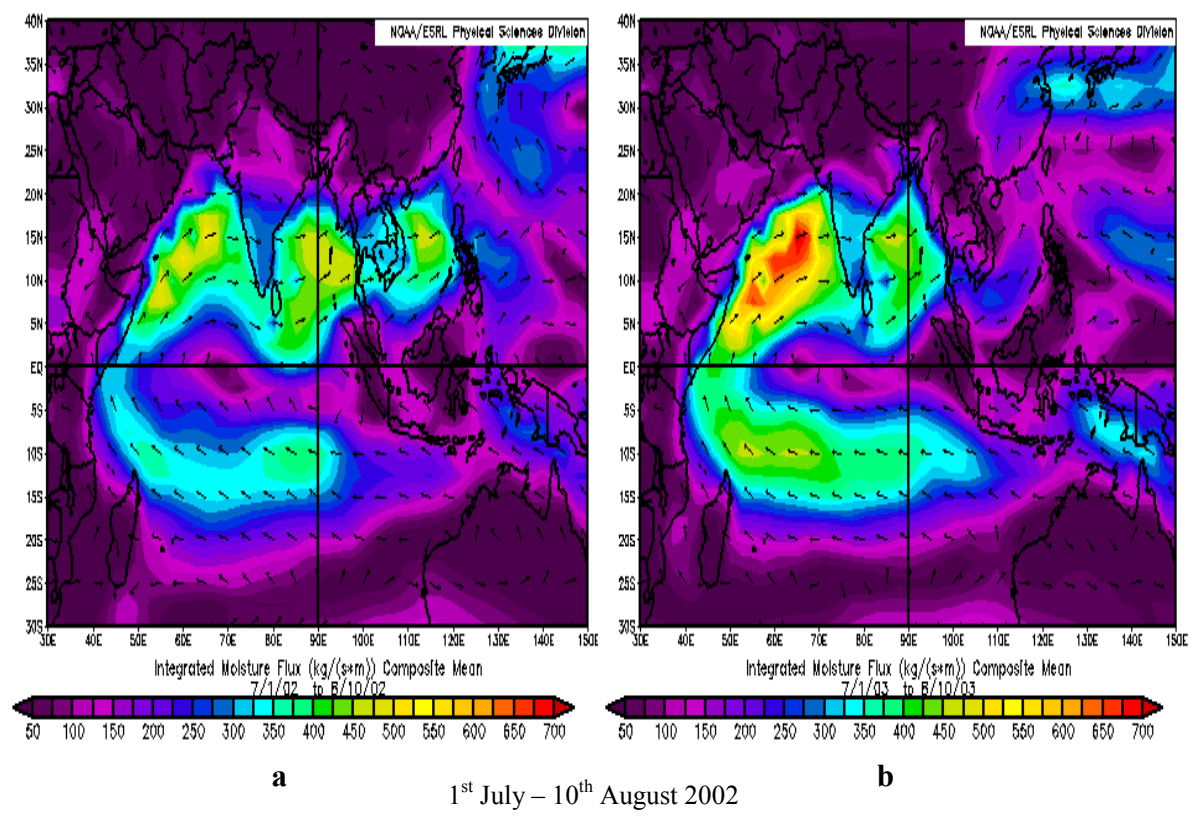

Fig. 9. Analysis of different parameters during 1 July-10 August for the years 2002-2003. (a), (b) Integrated moisture flux (1000-300 hPa) 2002 and 2003, respectively.

Of these the major contributor is the $f \nabla \psi \cdot \nabla \chi$ term. Compared to the other two terms in Eq. (4) all the energy terms in the boxes have their units in $\mathrm{m}^{2} \mathrm{~s}^{-3}$. As mentioned earlier we divided the monsoon period into three phases, before the break, during the break, and after the break, to delineate the changes.

\subsubsection{Before the break period (10 June-30 June)}

The conditions before the break are shown in the Fig. 10a for the two years. Although in the year 2003, there was no break, we use the same calendar period to compare and contrast. The tendency of Perturbation Available Potential Energy $\left(\partial P^{\prime} / \partial t\right)$ has the values 346.26 units and 336.91 units in the years 2002 and 2003, respectively. $-<\omega^{\prime} T^{\prime}>$, has 
2002(June 10- June 30)

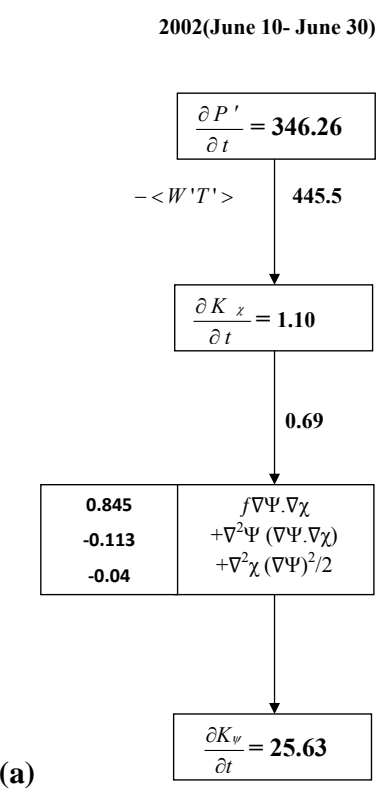

(a)

(c)

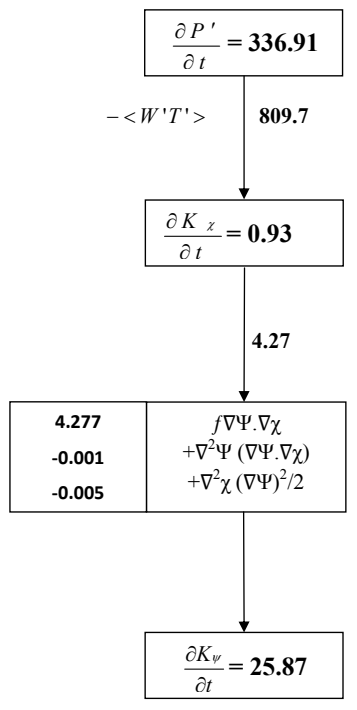

2002(August 11- August 30)

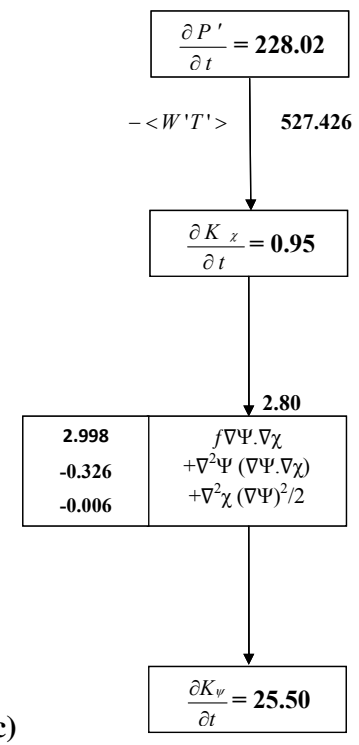

(b)
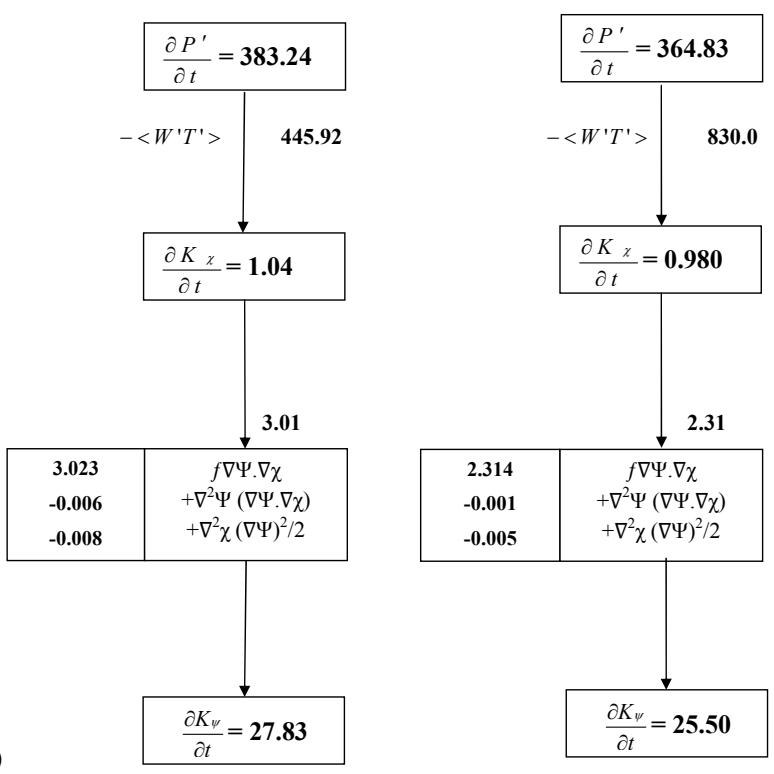

2003(August 11- August 30)

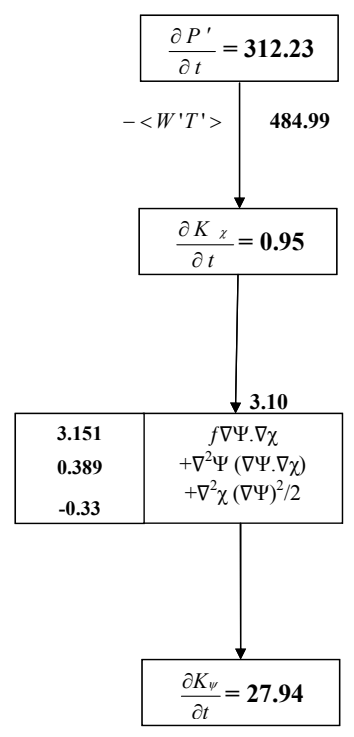

Fig. 10. Different energy exchanges are shown in the boxes and their time rates of change in units is $\mathrm{m}^{2} \mathrm{~s}^{-3}$. These are the mean values over the domain $30^{\circ} \mathrm{S}-40^{\circ} \mathrm{N}, 30^{\circ} \mathrm{E}-150^{\circ} \mathrm{E}$ and $1000 \mathrm{hPa}$ to $100 \mathrm{hPa}$ for the before break, break, after break shown in panels (a), (b), (c), respectively.

its value 445.5 units in the year 2002 which is small compared to 809.7 units for the year 2003. In the upper layers of the atmosphere the contribution of sensible heating is small. The condensation heating is expected to be the principal contributor for the generation if this heating is correlated strongly with temperature, while the radiative heating is expected to be a sink or small. Higher conversion from Poten- tial to divergent kinetic energy $<P^{\prime}, K^{\prime}>$ is noted for the year 2003 and its value is 809.7 units, and 445.5 units in the case of 2003. The year 2002 shows its peculiarity in the rainfall and energy even from the beginning of the monsoon season as noted earlier. $f \nabla \psi \cdot \nabla \chi$ shows a positive value 4.27 for the good year 2003 monsoon and a value of 0.69 for the year 2002. After the conversion from divergent to rotational 


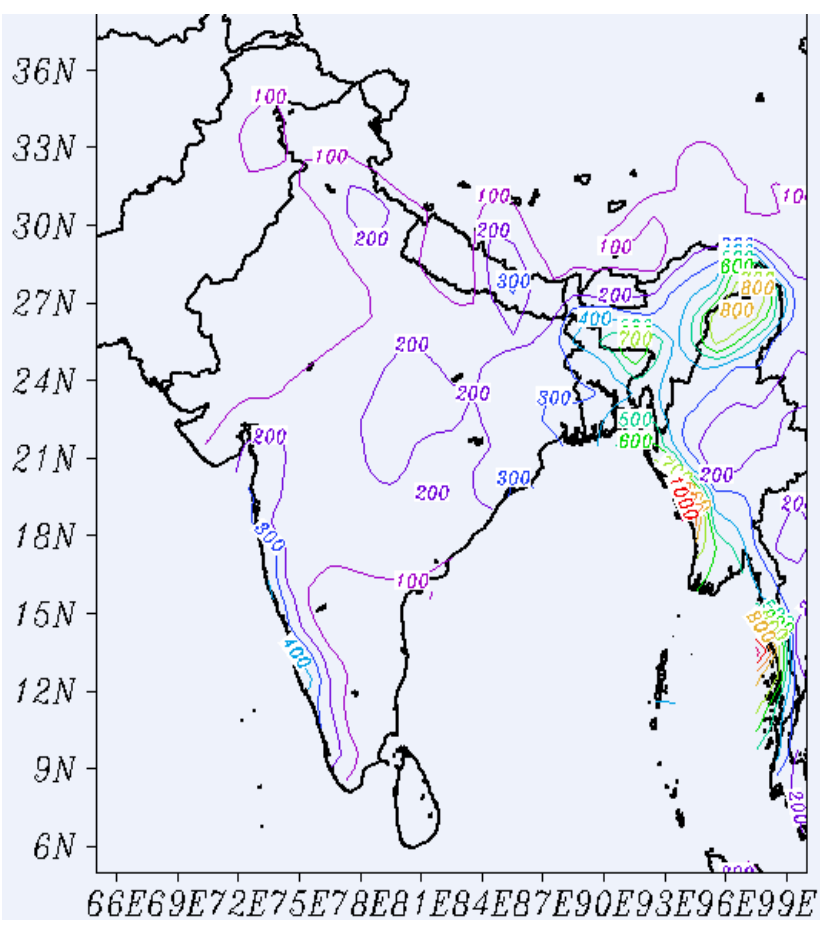

Fig. 11. NCEP rainfall (mm) 2002 (JJAS).

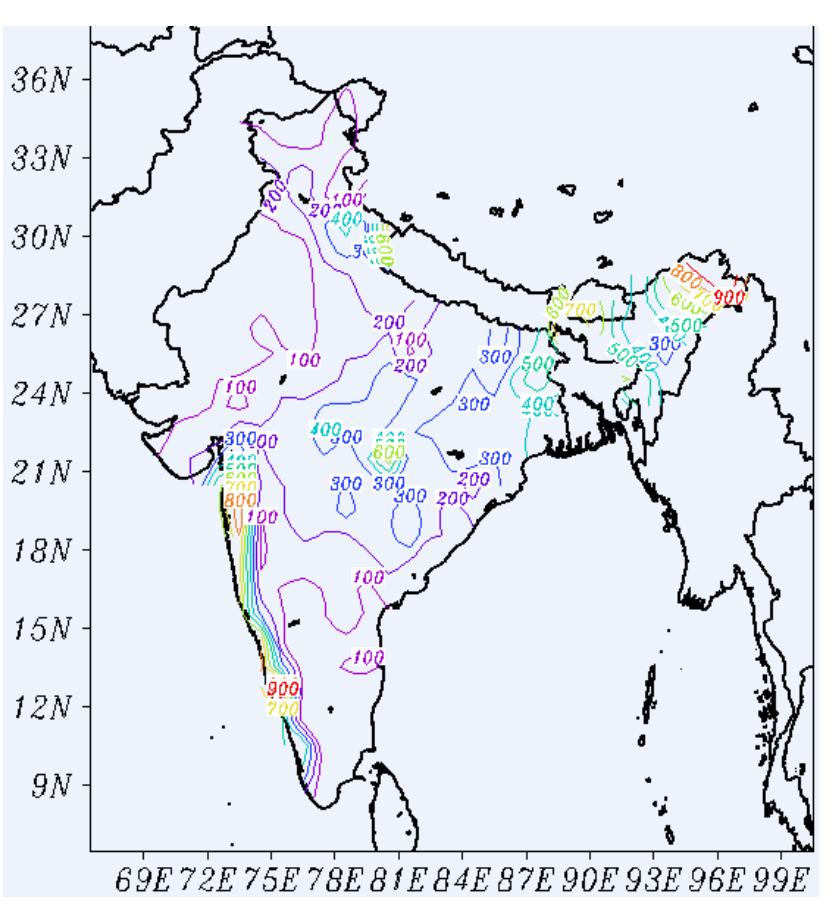

Fig. 12. IMD rainfall (mm) 2002 (JJAS).

kinetic energy, $\left(\frac{\partial K \psi}{\partial t}\right)$ has its value 25.63 units in the year 2002 and 25.87 units in the year 2003. A maximum positive conversion from divergent to rotational kinetic energy leads to wet spell conditions in the month of June for the year 2003

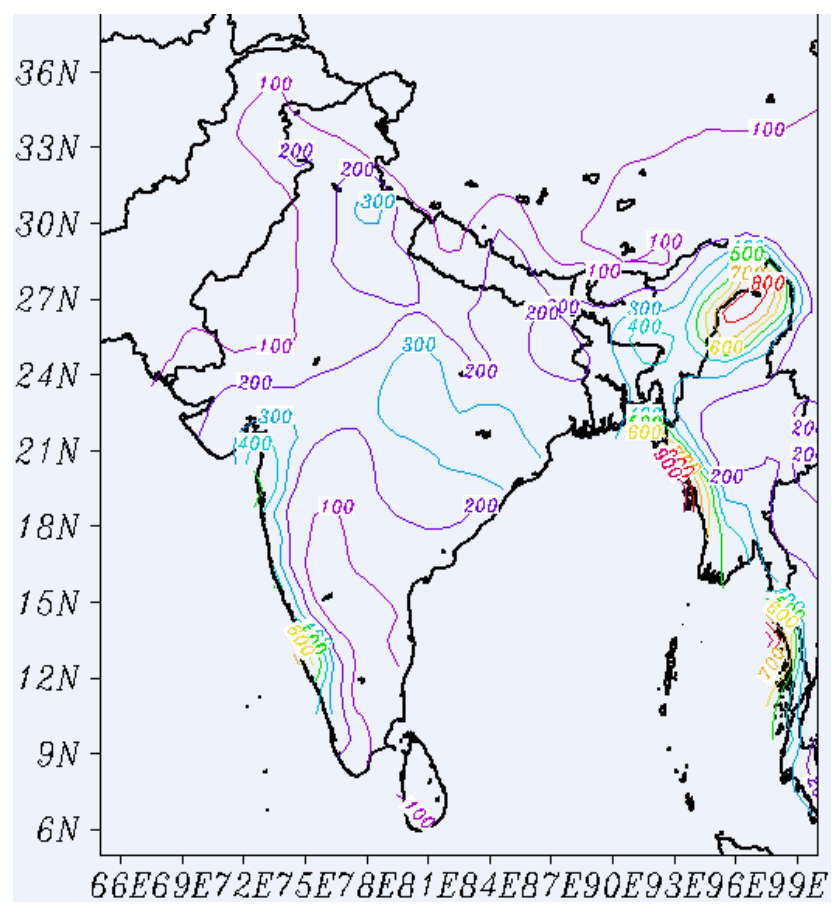

Fig. 13. NCEP rainfall (mm) 2003 (JJAS).

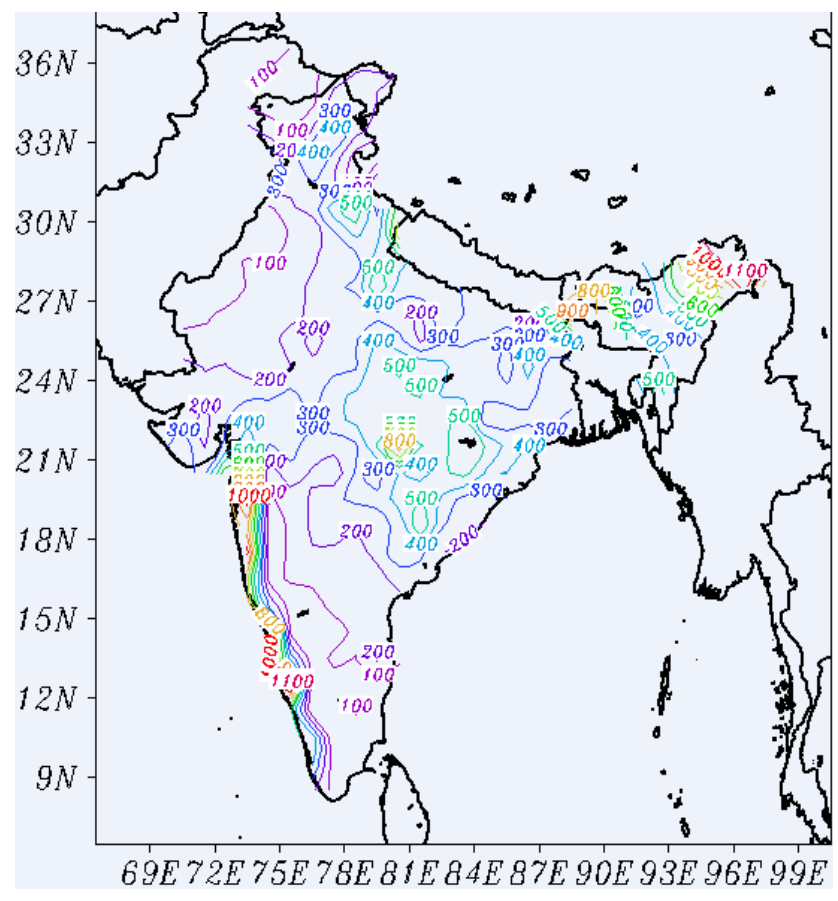

Fig. 14. IMD rainfall (mm) 2003 (JJAS).

and very small value of 0.69 from divergent to rotational kinetic energy seems to result in dry spell conditions for the year 2002. We were able to observe the complex behavior of 2002 from the beginning of the season through the block diagram shown in Fig. 10a. 
Table 1. Correlation coefficient between rainfall and $K_{\Psi}, K_{\chi}$, $f \nabla \Psi \cdot \nabla \chi$ for 2002 and 2003. * Significant at 0.05 level $(95 \%)$, $* *$ significant at 0.01 level (99\%)

\begin{tabular}{lcrr}
\hline \multicolumn{1}{c}{ Levels } & & 2002 & 2003 \\
\hline At $850 \mathrm{hPa}$ & $K_{\Psi}$ & 0.129 & 0.037 \\
& $K_{\chi}$ & $*$ & \\
& & 0.230 & -0.002 \\
& $f \nabla \Psi \cdot \nabla \chi$ & -0.036 & 0.003 \\
\hline Column integration & $K_{\Psi}$ & 0.154 & $* *$ \\
$(1000-100 \mathrm{hPa})$ & & & 0.254 \\
& $K_{\chi}$ & 0.004 & -0.073 \\
& $f \nabla \Psi \cdot \nabla \chi$ & $* *$ & \\
& & -0.270 & -0.006 \\
\hline
\end{tabular}

\subsubsection{Break period (1 July-10 August)}

We try to explain the drought conditions in the year 2002 by comparing with the good rainfall year 2003 for the same period. The boxes in the Fig. 10b indicate the period of break of 2002. The time tendency of APE values 383.24 units and 364.83 units, do not have much variations in the years 2002 and 2003. During this period $-<\omega^{\prime} T^{\prime}>$, had a lower value of 445.92 units in the year 2002 compared to its value of 830.0 in 2003. ( $\left.\frac{\partial K \chi}{\partial t}\right)$ in the year 2002 did not change much compared to the pre-break conditions value shown in the Fig. 10a. During the break period, the time tendency of divergent kinetic energy did not change from the earlier period. But the conversion term $f \nabla \psi . \nabla \chi$ is higher and thus the time tendency of rotational kinetic energy increased in the year 2002. While in the year 2003, this term decreased, but in the time tendency of rotational kinetic energy did not decrease. This shows the role of the boundary flux terms which we did not calculate in this paper.

Thus the main difference between the before break and during the break period is we noted only in the $-<\omega^{\prime} T^{\prime}>$ term which is much higher in the higher rainfall year 2003 (809.7 and 830.0) compared to the lower rainfall year 2002 (445.5 and 445.9). This is interesting because the generation of perturbation available potential energy is higher in these two periods in 2002 (346.26 and 383.24) compared to the higher rainfall year 2003 (336.9 and 366.8). This again shows as mentioned earlier that the higher rainfall alone need not generate higher available potential energy

\subsubsection{After break (11 August-30 August)}

In Fig. 3a it is observed that the rainfall started increasing from 11 August to above normal value. In order to understand the variability of the monsoon a closer look in the conditions prevailing after a break is also important. Figure 10c indicates the period after the break. The tendency of APE decreased after the break in the year 2002 (from 383.24 to
228.02) probably because of low rainfall and low generation of APE. Although in 2003 it decreased from 364.83 to 312.23 as well, the variations between the three periods are much less. For the entire monsoon period from 10 June30 August, the total conversion from $P^{\prime} \rightarrow K^{\prime}$ in 2002 was $1418.8 \mathrm{~m}^{2} \mathrm{~s}^{-3}$ and in 2003 it was $2124.7 \mathrm{~m}^{2} \mathrm{~s}^{-3}$. This shows that the East-West direct thermal circulations make the difference between the weak and strong monsoon years. Also the rotational kinetic energy $\left(K_{\Psi}\right)$ is maintained from the $K_{\chi}$, through the term $f \nabla \Psi \nabla \chi$. With a view to see the connection between rainfall and energy terms we calculated the correlations (Table 1). In column integrated values there is a strong positive correlation between rainfall and $K_{\Psi}$ in the year 2003. Although, not significant the correlation is positive in 2002. This probably shows the role of $K_{\Psi}$ in the rainfall. The term $f \nabla \Psi \nabla \chi$ shows significant negative correlation in 2002. In 2003 also it is negative but not significant. At $850 \mathrm{hPa}$ level only $K_{\chi}$, shows a significant positive correlation in the year 2002.

\section{Conclusions}

A study of the energetics for two contrasting monsoon years 2002 and 2003 has been presented. From the results it is observed that a steady raise in the Total KE together with rainfall indicates that summer monsoon is a season of highest energy. During the onset of monsoon in 2002 and 2003, the sharp raise of total KE is clearly seen, which agrees well with the hypothesis of the dynamical onset proposed by Krishnamurti (1982). The conversion term $-<\omega^{\prime} T^{\prime}>$ plays a very important role in furnishing energy to drive the divergent circulation. A careful analysis of the energetics of 2002 and 2003 reveals that for the entire monsoon season in the year of higher rainfall 2003 this conversion was higher compared to the weak monsoon year 2002. Thus, the east-west direct thermal circulations and the conversion of potential energy to kinetic energy make the difference for the good and bad monsoons. In both years the term $f \nabla \Psi \nabla \chi$ converts $K_{\chi}$ to $K_{\Psi}$. It is found that before and during the break, the generation of the perturbation available potential energy is higher in 2002. This confirms that the correlation between the heating and the temperature rather the heating alone generates available potential energy and this can be higher in low rainfall year.

The correlation between the rainfall and energy parameters shows that $K_{\Psi}$ strongly correlates with rainfall in the higher rainfall year of 2003. The term $f \nabla \Psi \nabla \chi$ shows significant negative correlation in 2002.

To verify how sensitive the results are, to use of NCEP/NCAR reanalysis, we repeated the calculations with ECMWF reanalysis, ERA data. The results showed that the quantitative differences between the two are small and thus the conclusions of this study using NCEP/NCAR reanalysis data are robust. In the present study, in Table 1 
we showed the correlations with IMD rainfall data, not with NCEP/NCAR reanalysis rainfall data. But, for the winds and temperature of the reanalysis, the heating is provided by rainfall of the reanalysis data. However, the winds and temperature of the NCEP/NCAR reanalysis are widely recognized as reliable. Rao et al. (2002) found that NCEP/NCAR rainfall over South America is defective, although some of the general features of observed rainfall are reproduced.

Figures 11, 12, 13 and 14 show the isohyets of total rainfall in the monsoon season taken from NCEP/NCAR reanalysis and IMD for the years 2002 and 2003. The higher rainfall in 2003 can be seen in both data sources. However, the rainfall seems to be less in NCEP/NCAR reanalysis compared to IMD data. Further large differences are seen in the reanalysis data near the Western Ghats with the reanalysis data showing substantially low rainfall. A detailed analysis of the differences will be the subject of a future study.

As mentioned earlier, reanalysis winds and temperatures are reliable despite the fact that the rainfall is poor in the reanalysis. This needs an explanation. Here we make some preliminary conjectures. In the tropical regions the source of kinetic energy is the available potential energy generated by heating. This is in contrast to the extra-tropics where available potential energy resides in the meridional temperature gradient. The available potential energy is generated by the correlation between the heating and temperature, not by heating alone. In the present paper we found that this generation can be higher in lower rainfall year, because the correlation between condensation heating and temperature can be higher even if the condensation heating or rainfall can be lower. Thus, the winds and kinetic energy can be better reproduced even if the rainfall is poor.

Further, in a recent paper, Bordini and Schneider (2008) showed that for the monsoons, in particular Asian monsoon, the feed backs between large-scale extra tropical eddies and the tropical circulations are essential. This again shows, even if the tropical condensation heating or rainfall is poor, probably winds and temperature can be better, because they partially depend on extra-tropical circulations.

Acknowledgements. Thanks are due to V. Jitendra, for helping in calculations. Thanks are also due to the reviewer for his critical comments. The authors express their sincere thanks to Department of Science and Technology, Government of India for their Financial Support through a Financial Grant ES/48/CTCZ/007/2005/25 Sep 2005.

Topical Editor P. Drobinski thanks one anonymous referee for her/his help in evaluating this paper.

\section{References}

Awade, S. T., Totagi, M. Y., and Bawiskar, S. H.: Wave to wave and wave to zonal mean flow kinetic energy exchanges during contrasting monsoon years, Pure Appl. Geophys., 120(3), 463$482,1982$.
Bordoni, S. and Schneider, T.: Monsoons as eddy-mediated regime transitions of the tropical overturning circulation, Nature Geosci., 1, 515-519, 2008.

Chen, T. C.: Global water flux and maintenance during FGGE, Mon. Weather Rev., 113, 1801-1819, 1985.

De, U. S. and Mukhopadhyay, R. K.: Breaks in monsoon and related precursors, Mausam, 53, 309-318, 2002.

Dimri, A. P.: The Contrasting Features of Winter Circulation during Surplus and Deficient Precipitation over Western Himalayas, Pure Appl. Geophys., 162(11), 2215-2237, 2005.

Goswami, B. N. and Ajayamohan, R. S.: Intraseasonal oscillations and predictability of the Indian summer monsoon, Proc. Ind. Nat. Acad. Sci., 67A(3), 369-383, 2001.

Holton, J. R.: An Introduction to Dynamical Meteorology, fourth edition, academic, San Diego, Calif., 2004.

Joseph, P. V., Eishcheid, J. K., and Pyle, R. J.: Interannual variability of the onset of the Indian Summer Monsoon and its Association with atmospheric features, El Nino and sea surface temperature anomalies, J. Climate, 7, 81-105, 1994.

Kalnay, E., Kanamitsu, M., Kistler, R., Collins, W., Deaven, D., Gandin, L., Iredell, M., Saha, S., White, G., Woollen, J., Zhu, Y., Leetmaa, A., Reynolds, R., Chelliah, M., Ebisuzaki, W., Higgins, W., Janowiak, J., Mo, K. C., Ropelewski, C., Wang, J., Jenne, R., and Joseph, D.: The NCEP/NCAR 40-Year Reanalysis Project, B. Am. Meteorol. Soc., 77, 437-471, 1996.

Kistler, R., Kalnay, E., Collins, W., Saha, S., White, G., Woollen, J., Chelliah, M., Ebisuzaki, W., Kanamitsu, M., Kousky, V., Dool, H. van den, Jenne, R., and Fiorino, M.: The NCEP-NCAR 50Year Reanalysis: Monthly means CD-ROM and documentation, B. Am. Meteorol. Soc., 82, 247-268, 2001.

Krishnamurti, T. N. and Ramanathan, Y.: Sensitivity of the monsoon onset to differential heating, J. Atmos. Sci., 39, 1290-1306, 1982.

Krishnamurti, T. N., Ardanuy, P., Ramanathan, Y., and Pasch, R.: On the onset vortex of the summer monsoon, Mon. Weather Rev., 109, 344-363, 1981.

Krishnamurti, T. N., Sinha, M. C., Bhaskar Jha, and Mohanty, U. C.: A study of South Asian monsoon energetics, J. Atmos. Sci., 55, 2530-2548, 1998.

Kung, E. C. and Paul, H.: Chan Energetics Characteristics of the Asian Winter Monsoon in the source region, Mon. Weather Rev., 109(4), 854-870, 1980.

Lorenz, E. N.: Available potential energy and the maintenance of the general circulation, Tellus, 7, 157-167, 1955.

Lorenz, E. N.: Energy and numerical weather prediction, Tellus, 12, 364-373, 1960.

Mishra, S. K. and Rao, V. B.: The Energetics of an upper tropospheric cyclonic vortex over north-east Brazil, Q. J. Roy. Meteorol. Soc., 127(577), 2329-2351, 2006.

Mohanty, U. C., Dube, S. K., and Sinha, P. C.: On the Role of Large Scale Energetics in the Onset and Maintenance of Summer Monsoon - II: Moisture Budget, Mausam, 33(3), 285-294, 1982.

Parthasarathy, B., Munot, A. A., and Kothawale, D. R.: All India monthly and seasonal rainfall series 1871-1993, Theor. Appl. Climatol., 49, 217-224, 1994.

Pisharoty, P. R. and Desai, B. N.: Western disturbances and Indian weather, Ind. J. Met. Geophys., VII, 333-338, 1956.

Rajeevan, M. J., Jyoti Bhate, J. D., Kale, J. D., and Lal, B.: High resolution daily gridded rainfall data for the Indian region: Anal- 
ysis of break and active monsoon spells, Current Sci., 91, 296306, 2006.

Raju, P. V. S., Mohanty, U. C., Rao, P. L. S., and Bhatla, R.: The contrasting features of Asian summer monsoon during surplus and deficient rainfall over India, Int. J. Climatol., 22(15), 18971914, 2002.

Ramage, C. S.: Monsoon Meteorology, Academic Press, New York, 296 pp., 1971.

Ramesh, K. J., Rao, P. L. S., and Mohanty, U. C.: A study on the distinct features of the Asian Summer monsoon during the years of extreme monsoon activity over India, Meteorol. Atmos. Phys., 59(3-4), 173-183, 1994.

Rao, V. B. and Rao, S. T.: A theoretical and synoptic study of western disturbances, Pure Appl. Geophys., United States, 90, 193 208, 1971.
Sikka, D. R.: Some aspects of the large scale fluctuations of summer monsoon rainfall over India in relation to fluctuations in the planetary and regional scale circulation parameters, J. Earth Syst. Sci., 89(2), 179-195, 1980.

Shukla, J.: Interannual variability of monsoon, in: Monsoons, edited by: Fein, J. S. and Stephens, P. L., John Wiley and Sons, New York, 399-464, 1987.

$\mathrm{Xu}$ Jianjun and $\mathrm{Wu}$ Guoxiong: Dynamic features and maintenance mechanism of Asian summer monsoon subsystem, Adv. Atmos. Sci., 16(4), 523-536, 1999. 